\title{
Effects of changes in climatic variability on agricultural production
}

\author{
Qunying Luo ${ }^{1,5, *}$, William Bellotti ${ }^{2}$, Peter $\operatorname{Hayman}^{3}{ }^{3}$ Martin Williams $^{1}$, Peter Devoil ${ }^{4}$ \\ ${ }^{1}$ Department of Geographical and Environmental Studies, University of Adelaide, Adelaide, South Australia 5005, Australia \\ ${ }^{2}$ School of Agriculture and Wine, University of Adelaide, Adelaide, South Australia 5371, Australia \\ ${ }^{3}$ South Australian Research and Development Institute, GPO Box 397, Adelaide, South Australia 5001, Australia \\ ${ }^{4}$ Department of Employment, Economic Development and Innovation, Toowoomba, Queensland 4350, Australia \\ ${ }^{5}$ Plant Functional Biology and Climate Change Cluster, University of Technology, Sydney, New South Wales 2007, Australia
}

\begin{abstract}
Daily outputs of the CSIRO Conformal Cubic Atmospheric Model (C-CAM) for the periods of 1961-1990 and 2065-2094 were used in the present study to derive changes in mean climate and in climatic variability, which were used by the stochastic weather generator LARS-WG to generate climatic change scenarios for 3 sites in southeast Australia. Climatic scenarios were coupled with the Agricultural Production System sIMulator (APSIM)-Wheat/Canola models to identify the influence of changes in climatic variability on wheat and canola production at 3 sites (Condobolin, Nhill and Wagga Wagga). Changes in climatic variability had negative effects on average wheat and canola yields at Wagga Wagga and Condobolin, and, in most cases, on the coefficients of variation (CV) of wheat yield, while the CV of canola yield experienced both positive (50\% of the cases) and negative $(50 \%$ of the cases) effects. Changes in climatic variability had positive (50\% of the cases) or no (50\% of the cases) effect on the average harvest index (HI) of wheat, whereas they had negative (33\% of cases) or no $(67 \%$ of cases) effect on the average $\mathrm{HI}$ of canola. Negative effects of changed climatic variability on the CV of $\mathrm{HI}$ for both crops were found. Our results demonstrate that the effects of changes in climatic variability on crop production vary across locations and impact indicators. Changes in climatic variability therefore need to be taken into account in agricultural impact assessment.
\end{abstract}

KEY WORDS: Australia · Climatic change - Climatic variability · Crop yields · Harvest index · LARS-WG

\section{INTRODUCTION}

A feature of most previous agricultural impact assessment studies is that changes in mean climate parameters, such as mean rainfall and mean maximum/ minimum temperatures, have been used in crop models to quantify their effects on crop production. The possible impacts on crop production from changes in climatic variability (e.g. the length of wet and dry spells, and temperature variability) have been ignored in most previous studies. The focus on mean climatic change has provided useful but limited information on how future changes in climatic variability (through extreme events such as drought and extreme high temperatures) might affect agriculture (Mearns et al. 1997). It has long been recognised that changes in climatic variability can have serious effects on agricultural yield (Parry \& Carter 1985). One of the main means by which crops are affected is through changes in the frequency of extreme climatic events (e.g. heat waves, droughts) (Mearns et al. 1984, Semenov \& Barrow 1997). Changes in climatic variability have a greater effect on the frequency of extremes than changes in mean climate (Katz \& Brown 1992). The possible impact of changes in climatic variability aroused attention in the early 1990s.

Several earlier studies have tested the sensitivity of crop yield to changes in climatic variability using arbitrary changes in the variability of temperature and rainfall (Mearns et al. 1992, 1996, 1997, Riha et al. 1996, Luo \& Lin 1999). The potential impacts of changes in climatic variability and in mean climate (derived from 
general circulation model [GCM] outputs) on crop production have also been performed. For instance, Semenov \& Barrow (1997) examined the importance of changes in climatic variability on wheat yields in Spain based on outputs of a transient GCM (UKTR) and found that there were significant differences in the distribution of wheat yield once changes in climatic variability were taken into account. Mearns et al. (1997) investigated the impacts of changes in climatic variability on wheat yields in the USA by using the outputs of a regional climate model (RCM). Torriani et al. (2007) quantified the effects of changes in mean climate and in climatic variability on the yield of winter and spring crops in Switzerland. There has been recent progress in this field, with expanded computer resource volume, daily outputs of GCMs/RCMs ever more widely available, and longer term simulation of GCMs/RCMs at daily time steps, enabling stable signals of climatic change to be obtained. There has also been progress in GCM performance in simulating the behaviour of climatic variability, in downscaling techniques, and in the coupling techniques between the outputs of GCMs/RCMs and crop models. For example, Semenov (2007) developed a methodology for incorporating changes in climatic variability into climatic change scenarios for agricultural risk assessment. Climatic change scenarios constructed in this study are more robust than the direct use of the 30 year downscaled daily outputs of GCMs as the latter may encompass bias from the climate model itself without integrating with historical climate data. Another advantage of this approach is that climatic change scenarios of longer time series can be generated, which are appropriate for risk assessment rather than short time series such as 30 years. These advances stimulated us to study the potential impacts of changed climatic variability on cropping systems in southeast Australia. Building on recent developments in climatic change modelling, our study aims to quantify the effects of changes in climatic variability on crop production in southeast Australia. Our wider objective is to show that changes in climatic variability need to be taken into account in agricultural impact assessment rather than simply relying upon mean climate change.

\section{MATERIALS AND METHODS}

\subsection{Study sites and background}

The present study focused on 3 locations: Condobolin, Nhill and Wagga Wagga in southeast Australia (Table 1). Nhill and Wagga Wagga are located in medium rainfall areas with growing season (GS; May to October inclusive) rainfall of 265 and $312 \mathrm{~mm}$, respec-
Table 1. Study locations, annual and growing season rainfall (GSR; May-October, inclusive)

\begin{tabular}{|lccccc|}
\hline Station & Lat. & Long. & $\begin{array}{c}\text { Altitude } \\
(\mathrm{m})\end{array}$ & $\begin{array}{c}\text { Annual } \\
\text { rainfall } \\
(\mathrm{mm})\end{array}$ & $\begin{array}{c}\text { GSR } \\
(\mathrm{mm})\end{array}$ \\
& & & & & \\
\hline Condobolin & $33^{\circ} 04^{\prime} \mathrm{S}$ & $147^{\circ} 14^{\prime} \mathrm{E}$ & 195 & 449 & 218 \\
Nhill & $36^{\circ} 20^{\prime} \mathrm{S}$ & $141^{\circ} 38^{\prime} \mathrm{E}$ & 133 & 415 & 265 \\
Wagga Wagga $35^{\circ} 08^{\prime} \mathrm{S}$ & $147^{\circ} 18^{\prime} \mathrm{E}$ & 222 & 558 & 312 \\
\hline
\end{tabular}

tively, while Condobolin is located in a lower rainfall area with a GS rainfall of $218 \mathrm{~mm}$ (Table 1). Wagga Wagga and Nhill have a winter-dominant rainfall pattern, while Condobolin has an intermediate rainfall pattern between winter- and summer-dominant rainfall patterns (Fig. 1). GS rainfall amount is the key

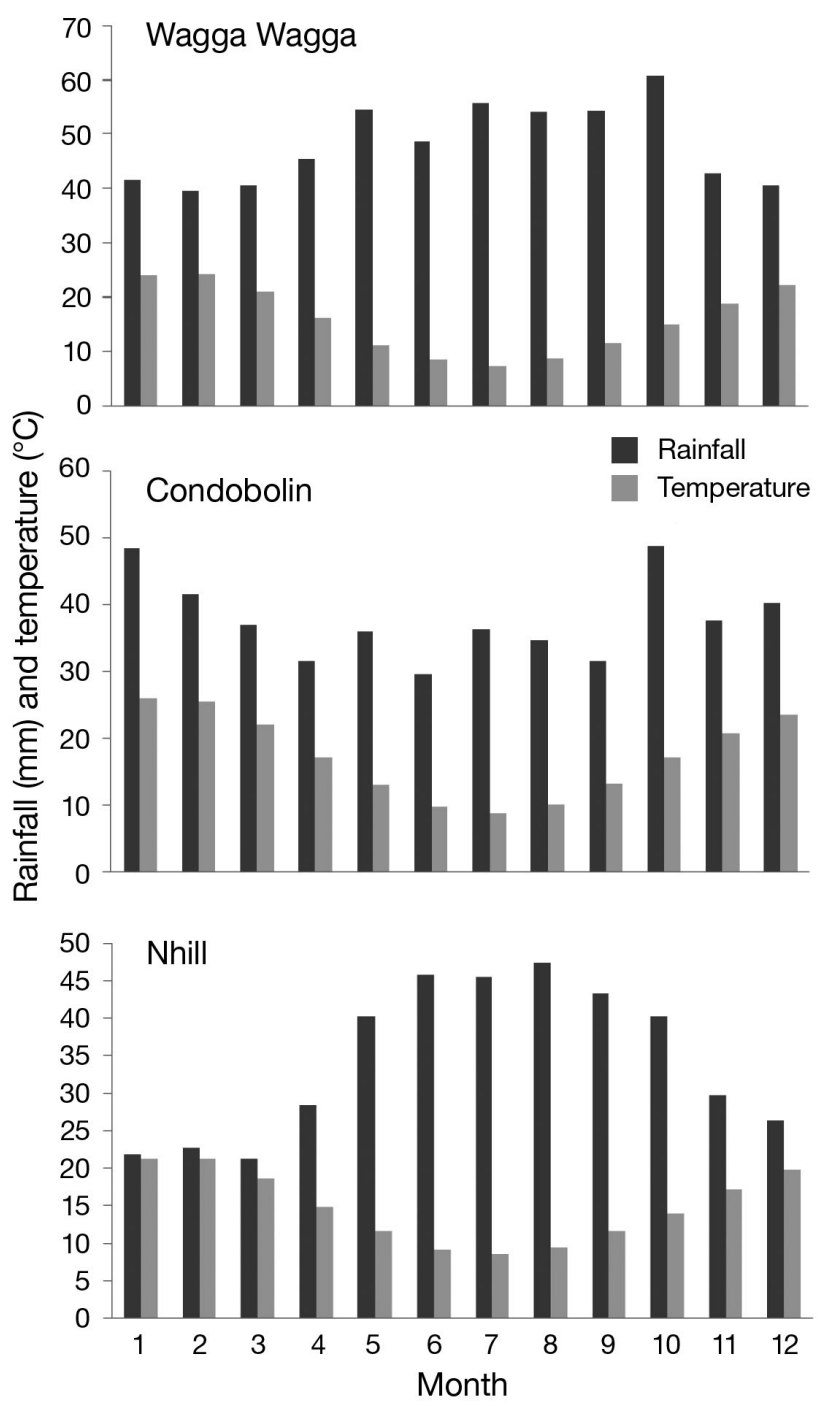

Fig. 1. Monthly mean rainfall and temperature of the 3 study locations 
determinant of dryland crop production levels, while starting rain (rainfall when sowing) is crucial for the successful establishment of the crop in the study region. The sowing window for crops in the study region ranges from April to August depending on seasonal break (starting rain) and crop types.

\subsection{Tools and data}

Computer simulation is one of the most important techniques used to quantify the potential impacts of climatic change on ecosystems. The Agricultural Production Systems sIMulator (APSIM)-Wheat/Canola models (version 5.0) were used in the present study to project crop yields and harvest indices (HI) under changed climatic conditions, including changes in both mean climate and in climatic variability. Daily rainfall, maximum and minimum temperature and solar radiation are common climatic inputs to the APSIM package. The APSIM model has been widely applied in climatic change/variability impact studies and in farming system studies in Australia, Europe and China. Description and validation of this model can be found in Keating et al. (2003), Luo (2003) and Yunusa et al. (2004).

\subsubsection{Climatic change projections and climatic change scenarios}

The Conformal-Cubic Atmospheric Model (C-CAM). It is well known that the direct outputs of GCMs cannot be used in impact assessment due to their coarse spatial resolution of hundreds of kilometres (Mearns et al. 2003, Wilby et al. 2004). They need to be downscaled before being used in impact assessment studies. Statistical and dynamic downscaling are common downscaling techniques. Methods of statistical downscaling include analogue-downscaling (Timbal et. al. 2008), circulation pattern downscaling/pattern scaling (Mitchell 2003) and synoptic downscaling (Charles et al. 2003). Dynamic downscaling comprises RCMs (McGregor 1997), High Resolution Limited Area Models (HRLAMs, Zhang et al. 2001) and variable resolution climate models (McGregor 2002). Dynamic downscaling has the advantage over statistical downscaling techniques that have frequently been used to increase the resolution of climate model results in that the resulting higher resolution climate is physically based, and the assumption of constancy of derived empirical relationships between large-scale and local climate conditions under perturbed climate conditions need not be made (Mearns et al. 1997).

For this reason, we have used dynamically downscaled outputs of C-CAM to derive changes in mean climate and in climatic variability and to construct climatic change scenarios for specific locations. This climate model is the only model that had dynamically downscaled outputs for application in Australia (McGregor 2002). C-CAM is a stretched-grid model, which has a roughly uniform grid $(50 \times 50 \mathrm{~km})$ over the area of interest and a reduced-resolution grid over the remainder of the globe. C-CAM was nested in the CSIRO Mk3.0 model fields and ran for the Special Report on Emission Scenarios (SRES) A2 scenario. The A2 scenario simulation includes changes in greenhouse gases, ozone and sulphate aerosol (direct effect only). It does not include changes in the solar constant, volcanic aerosols, the indirect effects of sulphate aerosols, nor changes in carbonaceous, mineral dust and sea salt aerosols (Dr. Tony Hirst pers. comm.). The C-CAM model performed quite well in the study region (Hennessy et al. 2004).

Derivation of climatic changes and construction of climatic change scenarios. Two periods, 1961-1990 centred on 1975 and 2065-2094 centred on 2080, representing current and future climates respectively, were used to derive monthly changes in mean climate and climatic variability in the present study. Mean climate refers to monthly mean temperature, monthly rainfall and monthly solar radiation. Climatic variability refers to the monthly mean duration of wet and dry spells and variability in monthly mean temperature. Derived monthly changes in mean climate and climatic variability were then used in a stochastic weather generator (LARS-WG) to produce 100 yr climatic change scenarios for 2080 based on the characteristics of historical climatic data covering the period 1958 to 2005 . The rationale for using this period of historical climatic data is that we have good quality temperature data since 1958. Detailed description of the LARS-WG can be found at www.rothamsted. bbsrc.ac.uk/mas-models/larswg.php, Semenov \& Stratonovitch (2010) and Luo et al. (2003). The performance of LARS-WG in diverse climates around the world was evaluated in Semenov et al. (1998), Qian et al. (2004) and Semenov (2008). To examine the effects of changes in climatic variability on crop production, 2 types of climatic change scenarios were developed. One considered changes in mean climate only. The other incorporated changes in both mean climate and climatic variability into climatic change scenarios.

\subsubsection{Soil}

To investigate the impact pattern of rising atmospheric $\mathrm{CO}_{2}$ and climatic change on crop production, we deliberately used the same soil profile for the locations under investigation. A sandy loam soil was used in the present study. Two levels of plant available water capacity (PAWC) were considered: high (161 mm) 
Table 2. Soil water and soil nitrogen used in the APSIMWheat/canola models. PAWC: plant available water capacity; Ll 15: lower limit at 15 bar; Dul: drained upper limit. Parentheses: soil condition with low PAWC

\begin{tabular}{|c|c|c|c|c|}
\hline \multirow{2}{*}{$\begin{array}{l}\text { Depth } \\
(\mathrm{mm})\end{array}$} & \multicolumn{2}{|c|}{-Soil water } & \multirow{2}{*}{$\begin{array}{c}\text { PAWC } \\
(\mathrm{mm})\end{array}$} & \multirow{2}{*}{$\begin{array}{c}\mathrm{NO}_{3} \\
\left(\mathrm{~kg} \mathrm{ha}^{-1}\right)\end{array}$} \\
\hline & $\begin{array}{c}\mathrm{Ll} \mathrm{15} \\
\left(\mathrm{mm} \mathrm{mm}^{-1}\right)\end{array}$ & $\begin{array}{c}\text { Dul } \\
\left(\mathrm{mm} \mathrm{mm}^{-1}\right)\end{array}$ & & \\
\hline 100 & 0.09 & 0.19 & 10 & 19.56 \\
\hline 250 & 0.1 & 0.21 & 16.5 & 23.51 \\
\hline 420 & 0.11 & 0.24 & 22.1 & 14.92 \\
\hline 700 & 0.11 & 0.24 & 36.4 & 22.51 \\
\hline $900^{\mathrm{a}}$ & 0.18 & 0.3 & 24 & 13.71 \\
\hline $1300^{\mathrm{a}}$ & 0.23 & 0.36 & 52 & 18.06 \\
\hline \multicolumn{3}{|l|}{ Total } & $161(85)$ & $112.27(80.5)$ \\
\hline
\end{tabular}

and low (85 mm) PAWC. The high PAWC corresponds to the original soil profile while the low PAWC is derived from the original soil profile with the 2 deepest soil horizons removed. Table 2 shows soil water and nitrogen parameters used by the APSIM-Wheat/ Canola Model.

\subsubsection{Simulation experimental design and model setting}

Two wheat cultivars, Chara and Janz, were considered in the present study. Chara is a mid-late maturity cultivar while Janz is an early maturing cultivar. Chara is sown when cumulative rainfall on 3 consecutive days is $\geq 20$ and $\geq 15 \mathrm{~mm}$ for medium (Nhill and Wagga Wagga) and low (Condobolin) rainfall areas, respectively, during the period of 15 April to 15 June. Janz is sown in the period of 16 June to 15 August with the same sowing criterion as Chara. If this condition can not be met, the wheat crop is forced to be sown on the last day (15 August) of the sowing window with Janz. Sowing depth is set at $3 \mathrm{~cm}$.

Similarly, 2 canola cultivars (Oscar and paCN145) were used in the present study. Oscar is sown when cumulative rainfall on 3 consecutive days is $\geq 20$ and $\geq 15 \mathrm{~mm}$ for medium and low rainfall area, respectively, during the period of 8 April to 7 May. paCN145 is sown in the period of 8 May to 7 June with the same sowing criterion as Oscar. If this condition cannot be met, the canola crop is forced to be sown on the last day ( 7 June) of the sowing window. Sowing depth is set at $2 \mathrm{~cm}$.

For both crops, soil water, nitrogen and wheat residue were reset to initial conditions on the 1st of March each year. Atmospheric $\mathrm{CO}_{2}$ concentration was set at $682 \mathrm{ppm}$ for 2080, which corresponds to the SRES A2 marker scenario. Other systematic information, such as amount of nitrogen application, wheat residue, and planting density, was set differently across rainfall areas and crops. In general, the higher the GS rainfall, the higher the amount of nitrogen and wheat residue applied and the higher the plant density. Table 3 details the information for these 3 inputs for the locations and crops considered in the present study.

\section{RESULTS}

\subsection{Climatic changes in 2080}

Table 4 summarises the growing season climatic change information for the 3 locations under study based on the monthly changes mentioned in section 2.2.1. Climatic variables include mean rainfall, length of wet and dry spells, mean temperature, variability of mean temperature and solar radiation for the period centred on 2080. There was a slight increase (1 to $2 \%$ ) in GS rainfall at Condobolin and Wagga Wagga and an $8 \%$ decrease at Nhill. Wet spells for GS decreased 15,

Table 3. Management information at sowing

\begin{tabular}{|lcccc|}
\hline Location & $\begin{array}{c}\text { N application } \\
\left(\mathrm{kg} \mathrm{ha}^{-1}\right)\end{array}$ & $\begin{array}{c}\text { Wheat residue } \\
\left(\mathrm{kg} \mathrm{ha}^{-1}\right)\end{array}$ & $\begin{array}{c}\text { Wheat density } \\
\left(\text { plants } \mathrm{m}^{-2}\right)\end{array}$ & $\begin{array}{c}\text { Canola density } \\
\left(\text { plants }^{-2}\right)\end{array}$ \\
\hline Condobolin & 25 & 1000 & 100 & 60 \\
Nhill & 75 & 2000 & 150 & 60 \\
Wagga Wagga & 75 & 2000 & 150 & 60 \\
\hline
\end{tabular}

Table 4. Ratio of changes in mean climate (except for temperature) and climate variability for the growing season in 2080 derived from monthly changes based on daily outputs of the C-CAM model. Ratio of change: 2080 value divided by corresponding baseline value; temperature: absolute change; wet/dry series: spell (length) of rainy/non-rainy days; mean climate includes the parameters rainfall, temperature and radiation; climate variability includes wet/dry series and temperature variability

\begin{tabular}{|lcccccc|}
\hline Location & Rainfall & Wet series & Dry series & Temperature $\left({ }^{\circ} \mathrm{C}\right)$ & Temperature variability & Radiation \\
\hline Condobolin & 1.02 & 0.95 & 1.18 & 2.12 & 1.07 & 1.02 \\
Nhill & 0.92 & 0.85 & 1.18 & 1.57 & 1.10 & 1.01 \\
Wagga Wagga & 1.01 & 0.87 & 1.19 & 2.04 & 1.03 \\
\hline
\end{tabular}


13 and $5 \%$ at Nhill, Wagga Wagga and Condobolin, respectively, while dry spells for the GS increased 18 to $19 \%$ across the 3 locations. Increases in average temperature ranged from $\sim 1.6$ to $2^{\circ} \mathrm{C}$, and average temperature variability increased from $\sim 7$ to $10 \%$. A 1 to $3 \%$ increase in solar radiation was found.

\subsection{Mean and coefficients of variation of crop grain yield}

Table 5 shows the mean and coefficients of variation $(\mathrm{CV})$ of wheat and canola crop yields under baseline and future climatic scenarios, which considered changes in mean climate only and changes in both mean climate and in climatic variability across the 2 soil conditions (high and low PAWC). Under both soil conditions, compared with baseline yield, average wheat grain yields slightly increased at Wagga Wagga and Condobolin and decreased at Nhill under mean climatic change scenarios owing to the small increase in GS mean rainfall at Wagga Wagga and Condobolin and the decrease at Nhill. When changes in climatic variability are incorporated into the mean climatic change scenarios, the average wheat grain yield decreased at Wagga Wagga and Condobolin indicating the potentially adverse effects of changes in climatic variability on wheat crop yields at those sites, but increased slightly at Nhill.

Average canola yields decreased under both climatic change scenarios and soil conditions. When changes in climatic variability were also considered, there was a greater decrease at Wagga Wagga and Condobolin. However, at Condobolin under high PAWC with mean climatic change scenario, the average canola yield increased compared with baseline. This once again demonstrated the negative impacts of changes in climatic variability on crop yields. The impact of the 2 types of climatic change scenarios on canola yield at Nhill is similar to that of wheat yield across the 2 soil conditions at this location.

From Table 5, it can be seen that, compared with mean climatic changes only, the CV (shown in parenthesis) of wheat grain yield increased across 3 locations and the 2 soil conditions under scenarios with both changes in mean climate and in climatic variability, except at Condobolin under low PAWC. The CV of canola yield increased at Wagga Wagga under high PAWC and at Condobolin under both soil conditions when changes in climatic variability were also considered. However, the CV of canola yield slightly decreased at Wagga Wagga under low PAWC and at Nhill across the 2 soil conditions under changed climatic variability compared with mean climatic change only.

Table 5. Mean $\left(\mathrm{kg} \mathrm{ha}^{-1}\right)$ and coefficients of variation (in parentheses) of crop yield in 2080. PAWC: plant available water capacity; MC: mean climate change; MC + CVA: changes in mean climate and climate variability

\begin{tabular}{|c|c|c|c|c|c|c|}
\hline \multirow{2}{*}{ Crop and location } & \multicolumn{3}{|c|}{- High PAWC } & \multicolumn{3}{|c|}{ - Low PAWC } \\
\hline & Baseline & $\mathrm{MC}+\mathrm{CVA}$ & $\mathrm{MC}$ & Baseline & $\mathrm{MC}+\mathrm{CVA}$ & $\mathrm{MC}$ \\
\hline \multicolumn{7}{|l|}{ Wheat } \\
\hline Wagga Wagga & $3868(30)$ & $3827(32)$ & 4090 (29) & $2934(31)$ & 2997 (33) & $3285(30)$ \\
\hline Condobolin & $1482(76)$ & $1611(70)$ & $1669(70)$ & $1360(75)$ & $1418(69)$ & $1494(70)$ \\
\hline Nhill & $2023(65)$ & $1895(78)$ & $1638(76)$ & $1803(64)$ & $1674(76)$ & $1521(75)$ \\
\hline \multicolumn{7}{|l|}{ Canola } \\
\hline Wagga Wagga & $2354(27)$ & $2134(30)$ & $2263(28)$ & $2022(28)$ & $1828(28)$ & $1989(29)$ \\
\hline Condobolin & 1007 (71) & $910(70)$ & $1011(69)$ & $960(71)$ & $849(70)$ & $931(69)$ \\
\hline Nhill & 1301 (59) & $1054(69)$ & $932(71)$ & $1253(58)$ & $1004(68)$ & $911(69)$ \\
\hline
\end{tabular}

Table 6. Mean and coefficients of variation (in parentheses) of wheat harvest index (HI) in 2080. See Table 5 for definitions

\begin{tabular}{|c|c|c|c|c|c|c|}
\hline \multirow{2}{*}{ Crop and location } & \multicolumn{3}{|c|}{ High PAWC } & \multicolumn{3}{|c|}{ - Low PAWC } \\
\hline & Baseline & $\mathrm{MC}+\mathrm{CVA}$ & $\mathrm{MC}$ & Baseline & $\mathrm{MC}+\mathrm{CVA}$ & $\mathrm{MC}$ \\
\hline \multicolumn{7}{|l|}{ Wheat } \\
\hline Wagga Wagga & $0.33(11)$ & $0.33(12)$ & $0.33(10)$ & $0.31(12)$ & $0.32(14)$ & $0.32(12)$ \\
\hline Condobolin & $0.28(23)$ & $0.30(25)$ & $0.28(21)$ & $0.28(24)$ & $0.29(25)$ & $0.28(23)$ \\
\hline Nhill & $0.30(21)$ & $0.29(25)$ & $0.28(23)$ & $0.29(22)$ & $0.28(25)$ & $0.28(23)$ \\
\hline \multicolumn{7}{|l|}{ Canola } \\
\hline Wagga Wagga & $0.30(0.7)$ & $0.30(1.5)$ & $0.30(1.4)$ & $0.30(1.0)$ & $0.30(2.1)$ & $0.30(2.3)$ \\
\hline Condobolin & $0.27(22)$ & $0.26(26)$ & $0.27(21)$ & $0.26(24)$ & $0.26(27)$ & $0.26(23)$ \\
\hline Nhill & $0.29(10)$ & $0.28(19)$ & $0.28(16)$ & 0.29 (11) & 0.27 (19) & $0.28(16)$ \\
\hline
\end{tabular}




\subsection{Average and coefficients of variation of crop harvest index}

Compared with mean climatic change only, the average wheat $\mathrm{HI}$ remained unchanged at Wagga Wagga and at Nhill under low PAWC and was enhanced at Condobolin and Nhill under high PAWC with changed climatic variability (Table 6). The mean canola HI was unchanged under changed climatic variability in comparison with mean climatic change only, except at Condobolin under high PAWC and at Nhill under low PAWC where decreases in average $\mathrm{HI}$ were found (Table 6).

Table 6 also shows that the HI CV (in parentheses) for both wheat and canola increased across the 3 locations and 2 soil conditions under changed climatic variability in comparison with only mean climatic change except for canola at Wagga Wagga under low PAWC.

\section{DISCUSSION AND CONCLUSIONS}

Daily outputs of the C-CAM model for the 30-yr periods centred on 1975 and 2080 were used in the present study to derive changes in mean climate and in climatic variability. The derived changes were reapplied to the LARS-WG to generate $100 \mathrm{yr}$ climatic change scenarios, which were then coupled with the APSIMWheat/Canola models to project crop yields and HI across 2 soil conditions. A decrease in the average length of wet series and an increase in the average length of dry series and temperature variability were projected by the C-CAM model for the period of 2065-2094 under the SRES A2 emission scenario at the 3 sites in southeast Australia analysed in this study. Changes in climatic variability reduced both mean wheat and mean canola yields at Wagga Wagga and Condobolin and increased both yields at Nhill when compared with changes in mean climate only. The reason for the increase of crop yields at Nhill may be attributed to higher median GS rainfall (with higher intensity but less frequency) under changed climatic variability compared to the other 2 sites. Negative impacts of changes in climatic variability on $\mathrm{CV}$ of wheat yield were also found in the majority of the cases (across locations and soil water conditions). Changes in climatic variability have both positive (50\% of the cases) and negative (50\% of the cases) effects on the CV of canola yield. Changes in climatic variability have positive $(50 \%$ of the cases) or no $(50 \%$ of the cases) effects on the average $\mathrm{HI}$ of wheat, while they have negative ( $33 \%$ of cases) or no ( $67 \%$ of cases) effects on the average HI of canola. Negative effects of changes in climatic variability on the $\mathrm{CV}$ of $\mathrm{HI}$ for both crops were found. Semenov \& Barrow (1997) also found negative effects on the mean and CV of wheat yield from changes in climatic variability. Our work has demonstrated that when changes in climatic variability are considered, differences exist in the mean and CV of yield and HI for both wheat and canola compared with mean climatic change only. This implies that changes in climatic variability need to be taken into account in agriculture impact assessment. Derivation of changes in climatic variability and their incorporation into climatic change scenarios should be taken as normal practice in agricultural impact assessments. In this way, uncertainties in the construction of local climate change scenarios, specifically, and in the agricultural impact assessment, more broadly, will be substantially reduced.

The present study examined the effects of changed climatic variability on 2 crops (wheat and canola) with 2 impact indicators (yield and HI) and 2 statistics considered (mean and CV). A robust research methodology in the construction of climatic change scenarios was adopted in terms of the integration of changes in climatic variability into climatic change scenarios and the use of LARS-WG in producing long time series climatic change scenarios based on historical climatic characteristics rather than direct use of downscaled daily outputs. This study contributes to the understanding of the effects of changes in climatic variability on crop production systems.

The present study bears a number of limitations. For example, limited number of emission scenarios and climate models were considered in this analysis. This study has focused on the effects of changes in climatic variability on crop production. Effects of management options were not directly addressed but were partially and indirectly considered as illustrated in Section 2.2.3. We note that uncertainty may exist in extrapolating from specific sites to the wider region. We also note that uncertainties may arise from the use of the weather generator to represent changed climatic variability and the crop models to capture the effects of changed climatic variability.

Acknowledgements. We thank Marine and Atmospheric Research, CSIRO, for providing us the daily outputs of C-CAM and M.A. Semenov, Rothamsted Research, UK, for providing the LARS-WG model. This project was supported by the Australian Research Council grant LP0348864.

\section{LITERATURE CITED}

Charles SP, Bates B, Viney N (2003) Linking atmospheric circulation to daily rainfall patterns across the Murrumbidgee River Basin. Water Sci Technol 48:233-240

Hennessy KJ, Page CM, McInnes KL, Jones RN, Bathols JM, Collins D, Jones D (2004) Climate change in New South Wales. Past climate variability and projected changes in 
average climate. Consultancy report for the New South Wales Greenhouse Office. CSIRO Atmospheric Research and Australian Bureau of Meteorology, Aspendale

Katz RW, Brown BG (1992) Extreme events in a changing climate: variability is more important than averages. Clim Change 21:289-302

Keating BA, Carberry PS, Hammer GL, Probert ME, and 19 others (2003) An overview of APSIM, a model designed for farming systems simulation. Eur J Agron 18 3-4:267-288

Luo Q (2003) Assessment of the potential impacts of climate change on South Australian wheat production. $\mathrm{PhD}$ thesis, The University of Adelaide

Luo Q, Lin E (1999) Study on the effects of climate variability on China's rice production under regional climate change scenarios. Acta Ecol Sin 19:557-559

Luo Q, Williams MAJ, Bellotti W, Bryan B (2003) Quantitative and visual assessment of climate change impacts on South Australian wheat production. Agric Syst 77:173-186

McGregor JL (1997) Regional climate modelling. Meteorol Atmos Phys 63:105-117

McGregor JL (2002) Regional climate simulations with a variable resolution global model. Abstr 2nd ICTP conference on detection and modeling of regional climate change. Abdus Salam Intl Centre for Theoretical Physics, Trieste, p 13

Mearns LO, Katz RW, Schneider SH (1984) Extreme hightemperature events: changes in their probabilities with changes in mean temperature. J Clim Appl Meteorol 23: 1601-1613

Mearns LO, Rosenzweig C, Goldberg R (1992) Effects of changes in interannual climate variability on CERESWheat yields: sensitivity and $2 \times \mathrm{CO}_{2}$ general circulation model studies. Agric For Meteorol 62:159-189

Mearns LO, Rosenzweig C, Goldberg R (1996) The effects of change in daily and interannual climate variability on CERES-Wheat: a sensitivity study. Clim Change 32: $257-292$

- Mearns LO, Rosenzweig C, Goldberg R (1997) Mean and variance change in climate scenarios: methods, agricultural applications, and measures of uncertainties. Clim Change 35:367-396

Mearns LO, Giorgi F, Whetton P, Pabon D, Hulme M, Lal M (2003) Guidelines for use of climate scenarios developed from regional climate model experiments. Data Distribution Centre of the Intergovernmental Panel on Climate Change. Available at www.ipcc-data.org/guidelines/ index.html

Mitchell TD (2003) Pattern scaling: an examination of the accuracy of the technique for describing future climates.

Editorial responsibility: Mikhail Semenov,

Harpenden, UK
Clim Change 60:217-242

Parry ML, Carter TR (1985) The effect of climatic variations on agricultural risks. Clim Change 7:95-110

Qian BD, Gameda S, Hayhoe H, De Jong R, Bootsma A (2004) Comparison of LARS-WG and AAFC-WG stochastic weather generators for diverse Canadian climates. Clim Res 26:175-191

Riha SJ, Wilks DW, Simoens P (1996) Impact of temperature and precipitation variability on crop model predictions. Clim Change 32:293-311

Semenov MA (2007) Development of high-resolution UKCIP02-based climate change scenarios in the UK. Agric For Meteorol 144:127-138

Semenov MA (2008) Simulation of extreme weather events by a stochastic weather generator. Clim Res 35:203-212

Semenov MA, Barrow EM (1997) Use of a stochastic weather generator in the development of climate change scenarios. Clim Change 35:397-414

Semenov MA, Stratonovitch P (2010) Use of multi-model ensembles from global climate models for assessments of climate change impacts. Clim Res 41:1-14

Semenov MA, Brooks RJ, Barrow EM, Richardson CW (1998) Comparison of the WGEN and LARS-WG stochastic weather generators for diverse climates. Clim Res 10: 95-107

Timbal B, Fernandez E, Zhihong L (2008) Generalization of a statistical downscaling model to provide local climate change projections for Australia. Environ Model Softw 24: 341-358

Torriani DS, Calanca P, Schmid S, Beniston M, Fuhrer J (2007) Potential effects of changes in mean climate and climate variability on the yield of winter and spring crops in Switzerland. Clim Res 34:59-69

Wilby RL, Charles SP, Zorita E, Timbal B, Whetton P, Mearns LO (2004) Guidelines for use of climate scenarios developed from statistical downscaling methods. Data Distribution Centre of the Intergovernmental Panel on Climate Change. Available at www.ipcc-data.org/guidelines/ index.html

> Yunusa IAM, Bellotti WD, Moore AD, Probert ME, Baldock JA (2004) An exploratory evaluation of APSIM to simulate growth and yield processes for winter cereals in rotation systems in South Australia. Aust J Exp Agric 44: $787-800$

Zhang H, Henderson-Sellers A, Pitman AJ, Desborough CE, McGregor JL, Katzfey JJ (2001) Limited-area model sensitivity to the complexity of representation of the land surface energy balance. J Clim 14:3965-3986

Submitted: January 19, 2009; Accepted: April 28, 2010 Proofs received from author(s): June 19, 2010 